(梀) 


\title{
Wirtschaftsinformatik kompakt
}

\author{
Lieferbare Titel:
}

Bächle Kolb, Einführung in die Wirtschaftsinformatik

Bächle Lehmann, E-Business

Deininger - Faust · Kessel, Java leicht gemacht

Heinrich, Allgemeine Systemanalyse

Heinrich, Operations Research

Heinrich - Mairon, Objektorientierte Systemanalyse

Kessel, Einführung in Linux

Preiß, Entwurf und Verarbeitung relationaler Datenbanken

Staab, Logik und Algebra

Stoll, IT-Management

Wirtz, Objektorientierte Programmentwicklung mit

Visual Basic .NET-Grundlagen 


\title{
E-Business
}

Grundlagen elektronischer Geschäftsprozesse im Web 2.0

\author{
von \\ Professor Dr. Michael Bächle \\ und \\ Professor Dr. Frank R. Lehmann \\ Duale Hochschule Baden-Württemberg Ravensburg
}


Bibliografische Information der Deutschen Nationalbibliothek

Die Deutsche Nationalbibliothek verzeichnet diese Publikation in der Deutschen Nationalbibliografie; detaillierte bibliografische Daten sind im Internet über $<$ http://dnb.d-nb.de> abrufbar.

(C) 2010 Oldenbourg Wissenschaftsverlag GmbH

Rosenheimer Straße 145, D-81671 München

Telefon: (089) 45051-0

oldenbourg.de

Das Werk einschließlich aller Abbildungen ist urheberrechtlich geschützt. Jede Verwertung außerhalb der Grenzen des Urheberrechtsgesetzes ist ohne Zustimmung des Verlages unzulässig und strafbar. Das gilt insbesondere für Vervielfältigungen, Übersetzungen, Mikroverfilmungen und die Einspeicherung und Bearbeitung in elektronischen Systemen.

Lektorat: Wirtschafts- und Sozialwissenschaften, wiso@oldenbourg.de

Herstellung: Anna Grosser

Coverentwurf: Kochan \& Partner, München

Gedruckt auf säure- und chlorfreiem Papier

Gesamtherstellung: Grafik + Druck GmbH, München

ISBN 978-3-486-58362-5 